\title{
ONREL
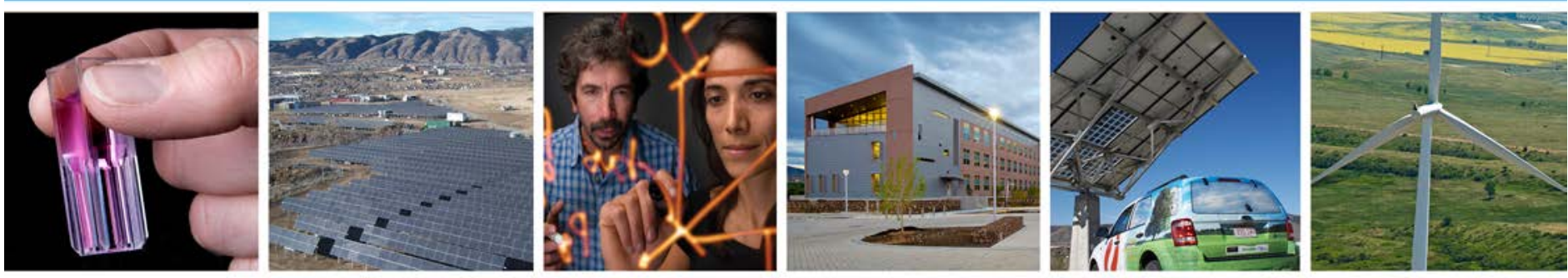

\section{Electric Energy Management in the Smart Home: Perspectives on Enabling Technologies and Consumer Behavior}

\section{Preprint}

\author{
A. Zipperer, P. A. Aloise-Young, \\ S. Suryanarayanan, and D. Zimmerle \\ Colorado State University \\ R. Roche \\ University of Technology of Belfort-Montbeliard \\ L. Earle and D. Christensen \\ National Renewable Energy Laboratory \\ P. Bauleo \\ Fort Collins Utilities \\ To be published in Proceedings of the IEEE
}

NREL is a national laboratory of the U.S. Department of Energy Office of Energy Efficiency \& Renewable Energy

Operated by the Alliance for Sustainable Energy, LLC

This report is available at no cost from the National Renewable Energy Laboratory (NREL) at www.nrel.gov/publications.

Journal Article

NREL/JA-5500-57586

August 2013

Contract No. DE-AC36-08GO28308 


\section{NOTICE}

The submitted manuscript has been offered by an employee of the Alliance for Sustainable Energy, LLC (Alliance), a contractor of the US Government under Contract No. DE-AC36-08GO28308. Accordingly, the US Government and Alliance retain a nonexclusive royalty-free license to publish or reproduce the published form of this contribution, or allow others to do so, for US Government purposes.

This report was prepared as an account of work sponsored by an agency of the United States government. Neither the United States government nor any agency thereof, nor any of their employees, makes any warranty, express or implied, or assumes any legal liability or responsibility for the accuracy, completeness, or usefulness of any information, apparatus, product, or process disclosed, or represents that its use would not infringe privately owned rights. Reference herein to any specific commercial product, process, or service by trade name, trademark, manufacturer, or otherwise does not necessarily constitute or imply its endorsement, recommendation, or favoring by the United States government or any agency thereof. The views and opinions of authors expressed herein do not necessarily state or reflect those of the United States government or any agency thereof.

This report is available at no cost from the National Renewable Energy Laboratory (NREL) at www.nrel.gov/publications.

Available electronically at http://www.osti.gov/bridge

Available for a processing fee to U.S. Department of Energy and its contractors, in paper, from:

U.S. Department of Energy

Office of Scientific and Technical Information

P.O. Box 62

Oak Ridge, TN 37831-0062

phone: 865.576.8401

fax: 865.576 .5728

email: mailto:reports@adonis.osti.gov

Available for sale to the public, in paper, from:

U.S. Department of Commerce

National Technical Information Service

5285 Port Royal Road

Springfield, VA 22161

phone: 800.553 .6847

fax: 703.605.6900

email: orders@ntis.fedworld.gov

online ordering: http://www.ntis.gov/help/ordermethods.aspx 


\title{
Electric Energy Management in the Smart Home: Perspectives on Enabling Technologies and Consumer Behavior
}

\author{
Adam Zipperer, Student Member, IEEE, Patricia A. Aloise-Young, Siddharth Suryanarayanan, Senior \\ Member, IEEE, Robin Roche, Member, IEEE, Lieko Earle, Member, IEEE, Dane Christensen, \\ Member, IEEE, Pablo Bauleo, Daniel Zimmerle, Member, IEEE
}

\begin{abstract}
Smart homes hold the potential for increasing energy efficiency, decreasing costs of energy use, decreasing the carbon footprint by including renewable resources, and transforming the role of the occupant. At the crux of the smart home is an efficient electric energy management system that is enabled by emerging technologies in the electricity grid and consumer electronics. This article presents a discussion of the state-of-theart in electricity management in smart homes, the various enabling technologies that will accelerate this concept, and topics around consumer behavior with respect to energy usage.
\end{abstract}

Index Terms - behavioral science, consumer behavior, decision making, energy management, load management, smart grid, smart home

\section{INTRODUCTION}

$\mathrm{A}$ smart home may be defined as a well-designed structure with sufficient access to assets, communication, controls, data, and information technologies for enhancing the occupants' quality of life through comfort, convenience, reduced costs, and increased connectivity [1]. The idea has been widely acknowledged for decades, but few people have ever seen a smart home, and fewer still have occupied one. A commonly cited reason for this slow growth has been the exorbitant cost associated with upgrading existing building stock to include "smart" technologies such as network connected appliances [1]. However, consumers have historically been willing to incur significant costs for new communi-

This work was supported in part by: the U.S. Department of Energy under Contract No. DE-AC36-08GO28308 with the National Renewable Energy Laboratory; US National Science Foundation Award \# 0931748; and the Program of Research and Scholarly Excellence (PRSE) grant from the Office of the Vice President for Research (VPR) at Colorado State University.

A. Zipperer, D. Zimmerle, P. Aloise-Young, and S. Suryanarayanan are with Colorado State University in Fort Collins, CO, United States (email: adam.zipperer@rams.colostate.edu).

R. Roche is with IRTES-SET at the University of Technology of BelfortMontbéliard in Belfort, France (email: robin.roche@utbm.fr).

L. Earle and D. Christensen are with the National Renewable Energy Laboratory in Golden, CO, United States (email: dane.christensen@nrel.gov).

P. Bauleo is with Fort Collins Utilities in Fort Collins, CO, United States (email: pbauleo@fcgov.com). cation technologies, such as cellular telephones, broadband internet connections, and television services. Table I presents the changes in US mean monthly income by quintiles and overall consumer spending on communication services, adjusted for 2011 USD [2]-[6].

TABLE I. US MONTHLY INCOME AND COMMUNICATIONS EXPENDITURES FOR 1980 AND 2008

\begin{tabular}{|l|c|c|c|}
\hline & $\mathbf{1 9 8 0}(\$)$ & $\mathbf{2 0 0 8}(\$)$ & Change (\%) \\
\hline Mean Income Quintile I & 4,310 & 11,656 & 170 \\
\hline Mean Income Quintile II & 10,727 & 29,517 & 175 \\
\hline Mean Income Quintile III & 17,701 & 50,132 & 183 \\
\hline Mean Income Quintile IV & 26,078 & 79,760 & 206 \\
\hline Mean Income Quintile V & 46,497 & 171,057 & 268 \\
\hline Communication Services & 22 & 117 & 432 \\
\hline
\end{tabular}

This information may indicate that consumers are not averse to significantly changing their spending habits with the advent of new technologies. According to the US Bureau of Labor Statistics the average homeowner spent approximately $11 \%$ more on entertainment (including cell phone and internet services) in 2010 than 25 years ago [2]. Data indicate that consumers are willing to spend more on hybrid vehicles than on similarly sized traditional vehicles for reasons other than economic payback [7].

Diverse motivations can lead to the same end goal. For instance, a consumer may purchase a hybrid vehicle to decrease carbon emissions, reduce dependency on foreign oil, save money, or simply as a status symbol. Regardless, driving a hybrid vehicle contributes to a more sustainable energy future by reducing oil consumption and greenhouse gas emissions. Similarly, marketing or societal influences may motivate consumers to invest in smart home technologies.

The authors contend that cost and the lack of perceived value have combined to slow the adoption of smart homes. However, the perceived value of a smart home is likely to vary across populations [8]. 
The US Energy Information Administration (EIA) estimates that $37 \%$ of end use electricity in the US is consumed in residences [4]. Concomitantly, household appliances, consumer electronics, and construction techniques are becoming increasingly efficient [5]. As the Smart Grid Initiative in the US progresses, the end-user is enabled with near-real time information from the service provider [9]. This presents an opportunity to coordinate the management of appliances and other loads in the smart home, considering information flow and end-user behavior.

This paper is organized as follows: section II describes a smart home; section III outlines the assets and control strategies in a smart home; section IV presents some enabling technologies; section V explains consumer energy behavior, especially in a residential environment; and, section VI offers concluding remarks.

\section{SMART Homes}

\section{A. What is a Smart Home?}

A home is already a well-designed connector for power transfer between the electricity grid and energy-consuming appliances. A smart home also functions as a switchboard for data flow among appliances and participants such as the enduser, the electric utility, and a third party aggregator [9], [10]. This evolved capability benefits stakeholders on both sides of the interface - utility customers, utilities, and third party energy management firms - because there are strong incentives for all sides to help the others function smoothly. For instance, a homeowner may not inherently care about the peak demand issues faced by the utility, but electricity prices and supply reliability are tied to operational practices of the service provider. On the other hand, a utility may be primarily concerned with meeting the requirements of public utility commissions, but unhappy ratepayers may result in business and regulatory risks.

Looking outward, a smart residential building has two-way communication with the utility grid, enabled by a smart meter, shown in Fig. 1, so that it can interact dynamically with the grid system, receiving signals from the service provider and responding with information on usage and diagnostics. A detailed description of the smart meter is provided in section IV. This bidirectional information exchange is enabled by the rapid adoption of advanced metering infrastructure (AMI).

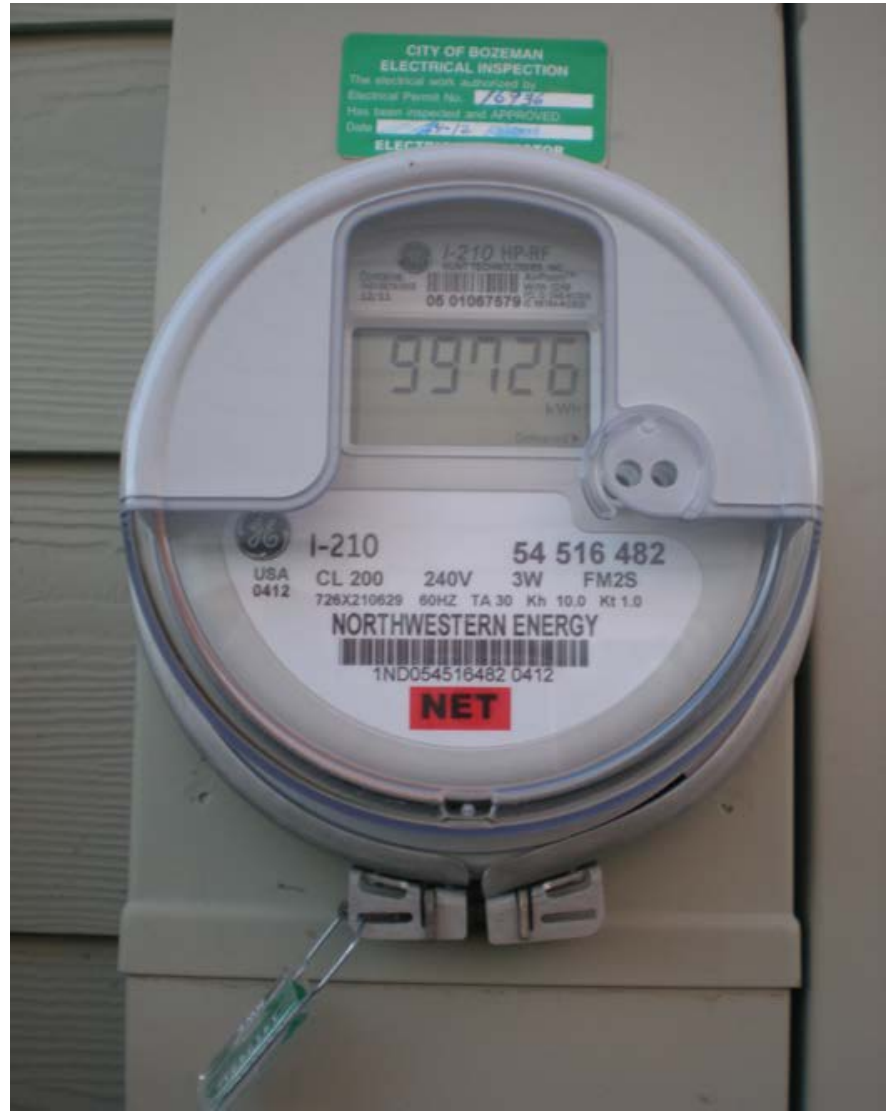

Fig. 1. A smart meter at a residence. Photo sourced from National Renewable Energy Laboratory (NREL) database, PIX 21394.

Looking inward, a smart home employs automated home energy management (AHEM), an elegant network that self manages end-use systems based on information flowing from the occupants and the smart meter. The value of AHEM is in reconciliation of the energy use of connected systems in a house with the occupant's objectives of comfort and cost as well as the information received from the service provider. Sensors and controls work together via a wireless home area network (HAN) to gather relevant data [11], process the information using effective algorithms, and implement control strategies that simultaneously co-optimize several objectives: comfort and convenience at minimal cost to the occupant, efficiency in energy consumption, and timely response to the request of the service provider [12]. An example of a smart home, constructed in a laboratory setting at NREL, is shown in Fig. 2. 


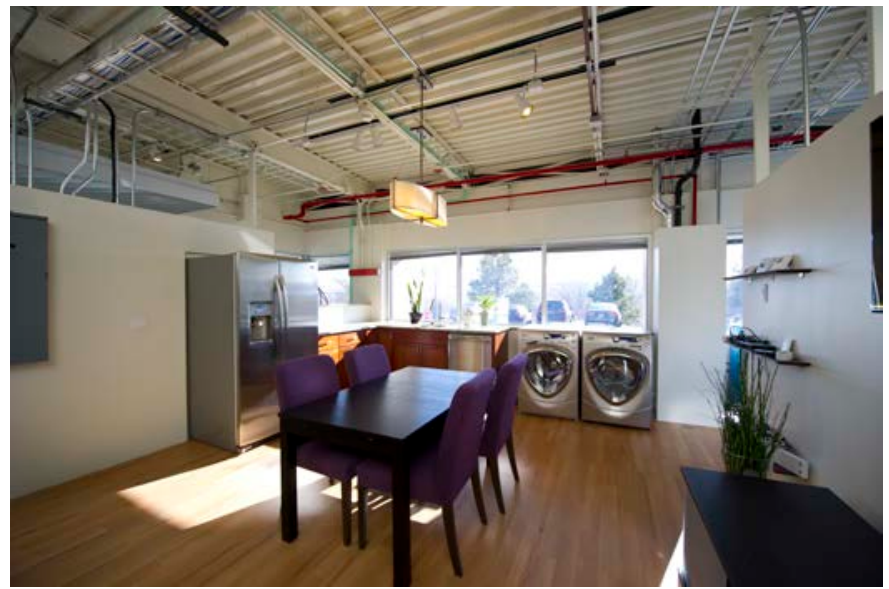

Fig. 2. NREL's AHEM laboratory. Photo sourced from NREL database, PIX 20207.

\section{B. Economic feasibility and likelihood of widespread adoption}

Several market and technology trends are expected to accelerate the development of cost-effective AHEM systems that enable smart homes. These include:

- Implementation of smart grids and continued growth in home offices will expand market penetration of secure HANs.

- Growth in web-based cloud computing applications will enable low-cost home energy data storage, data display, and data analysis for AHEM trend analysis [13].

- Advancements in smartphone technology such as batteries, user interfaces, and material [14], are expected to aid the development and adoption of AHEM systems.

- Manufacturers of residential equipment and appliances continue to embed additional sensors and control capabilities in new, smart home appliances that are internetready, can respond to requests from service providers, and offer advanced cycle controls such as multi-mode or variable speed controls and fault diagnostic sensors for space-conditioning equipment and "eco" modes for dishwashers, clothes washers, and other major appliances [15].

- Integration of energy services into other networked product offerings, such as security systems and television and telephony service.

A key strategy to engaging all stakeholders may lie in changes to the end-user electricity pricing structures - from fixed tariffs to dynamic prices that may change several times over a day - that reflect the use of the assets on the grid at any given time. If these structures are implemented to provide a tangible financial incentive for customers to respond to the requests of the service providers for demand reduction, the customers can receive measurable monetary value for their participation, in addition to the increased reliability of their service. Financial incentives are but one motivating factor for the adoption of smart homes.

\section{Smart Home Energy Management}

Large-scale demonstration efforts have thus far approached smart home research with a strong utility focus and less homeowner focus. Currently the incentive for homeowner participation is limited to relatively small financial gain via utility pricing structures; otherwise the motivation is primarily altruistic (i.e., environmental benefits). Most utilities offer incentives for energy upgrades such as attic insulation or ENERGY STAR ${ }^{\circledR}$ appliances and many have leveraged loadshedding technologies that cycle air conditioners during peak load events. Increasingly, utilities are funding more elegant efforts for on-request load reduction in the residential sector. For example, CPS Energy of San Antonio, Texas has partnered with Consert Inc. to demonstrate a load reduction system that can alter air conditioner and water heater set points and pool pump operation at the end-user facility during peak load times to enable substantial peak savings with limited impact on their customers [16]. This system is being rolled out to most residential customers in the San Antonio service territory.

Some utilities such as ComEd provide near-real time data to homeowners, along with several pricing structures and load reduction requests [17]. Many companies have recently incorporated web-based user interfaces, so a homeowner can adjust thermostat settings or turn off lights from a smartphone, as shown in Fig. 3 , or a web browser [15].

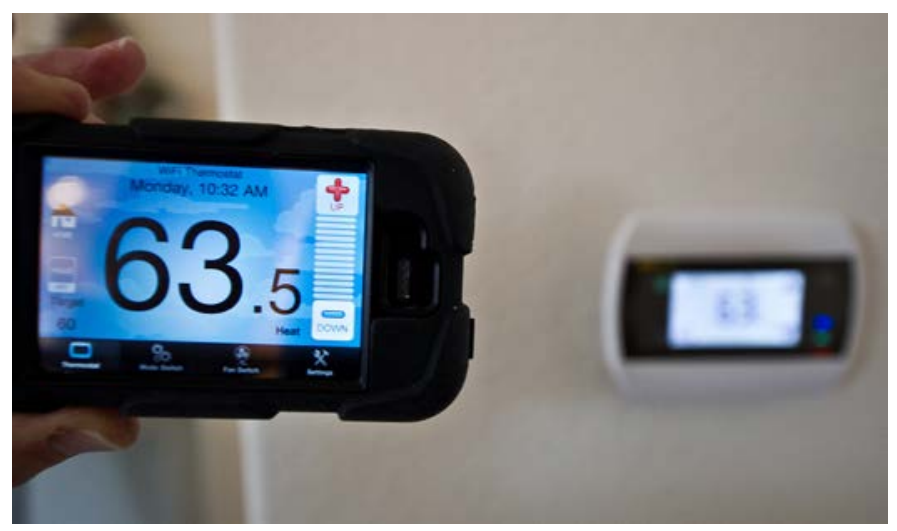

Fig. 3. A smartphone app for smart homes. Photo sourced from NREL database, PIX 20284.

Advanced grid measurements using AMI infrastructure are being rolled out in California and Texas [18]. These projects have multipronged focus of better integration of renewables, enhancement of efficiency, and optimization of consumer demands with utility needs on a community scale. Emerging nonintrusive load measurement systems can provide enabling data, but these modern measurement techniques are not yet robust, accurate, easy to install, or cost-effective for integration at the meter [19]. The available legacy methods for load disaggregation use algorithms supplemented with estimation, so the results may have less relevance to a given household than across an aggregated population [ ]. 


\section{ASSETS AND CONTROLS}

In smart homes, many loads can be considered as assets that can participate in the efficient use of electric energy: thermal loads, electric vehicles, and smart appliances. By intelligently controlling their behavior in either a reactive or a coordinated manner, these assets can provide leverage for energy and cost savings [20].

Thermal loads, such as air conditioning, electric space heating and water heating, can be controlled by "intelligent" thermostats. Contrary to traditional thermostats operating according to the hysteresis principle, an advanced thermostat such as the Nest has a learning capability that can automatically learn from user behavior patterns [21]. Then, the thermostat adapts the room temperature efficiently, e.g., by autoscheduling heating according to arrival and departure times and by detecting when the users are away [21], [22]. These strategies can help reduce energy consumption, especially when traditional or programmable thermostats are not configured properly, or cannot detect that users are away. Detailed control of household loads would allow the inherent thermal inertia of smart housing stock to be used for energy storage. The controller could "learn" the thermal response of the home, including factors such as weather forecasts, weather observations, and load levels from monitored devices. The resulting model would better predict future loads, which could be used locally or aggregated for the utility to plan short-term control options. For example, a smart home controller could pre-cool a house in the morning, before the system peak load, reducing air conditioning loads when signaled from the utility.

Plug-in electric vehicles, including hybrids, are expected to represent 1.7 to $3.5 \%$ of all US light duty vehicles by 2025 [23]. These correspond to a significant domestic load interfaced with power electronics that can also help make homes smarter. Using the vehicle-to-home technology, they can temporarily power the household, e.g., during demand peaks when power may become more expensive and the battery can provide a part of the total demand, or during outages by powering the entire household until the battery reaches its lower state-of-charge threshold [24], [25]. Adapting the charging schedule according to grid supply conditions offers additional possibilities, as described in section IV. The utility of such distributed storage may be improved when used together with distributed generationsources, such as photovoltaic panels [24].

A growing number of domestic loads, including electronics, solid-state lighting and variable-speed motors, use DC power internally. Most small, distributed, renewable energy sources generate DC power, which must be converted to AC for grid connection. Some recent work has considered household-sized distributed storage systems for local back-up power and ancillary service provision [26], [27]. The convergence of these sources and loads provides an interesting opportunity for significant advances in granular control of loads and high penetration of small-rated DC-powered assets.

A smart home could also integrate a low-voltage DC bus. Renewable resources, battery storage, and potentially vehicle charging could all interconnect on a DC bus. The DC bus would be integrated at a single point, and many inverters and converters would be reduced to DC-DC converters. When high volumes drive down costs, this simplification could reduce the cost and improve the efficiency of renewable systems, solid-state lighting and electronic loads. However, this paradigm shift presents challenges in electrical protection, re-wiring, and standardization. Presently, the EMerge Alliance is developing standards for DC distribution and usage, including $24 \mathrm{~V}$ and $380 \mathrm{~V}$ distribution systems [28]. Use of DC power distribution remains a retrofit challenge for existing US housing stock, but researchers are studying combined AC/DC distribution using existing building wiring [29].

Appliances also hold potential for smarter energy use. Dishwashers, washing machines and clothes dryers can be scheduled in advance, and do not need to be directly controlled by the user. The starting time can be postponed by several hours, with no impact on the user as long as the cycle is over when the user requested it initially. A similar strategy can be used to control freezer and refrigerator cycle so as to reduce peak demand by coordinating their operation [30]. Finally, many other loads can provide resources for smart energy use, and increase the comfort of the user, including automatic blinds that adjust based on daylight intensity, adaptive lighting, and autonomous vacuum cleaning robots. These devices exploit the possibilities offered by the extensive use of sensors, sometimes forming wireless sensor networks, and actuators controlled by smart, adaptive and possibly learning algorithms.

Almost all loads are, or could be, equipped with intelligent controllers, ranging from simple on/off control of state lighting, to sophisticated controllers for photovoltaic systems, vehicle chargers, and large loads such as air conditioning. With appropriate standardization and high volumes, practical, low-cost communication systems could connect most loads to a central household controller. The controller could provide detailed monitoring and control for occupants. With proper AMI interfacing, the home could further aggregate the resources for system uses, requested by the service provider. A block diagram of the centrally controlled smart home and its constituent assets is presented in Fig. 4. 


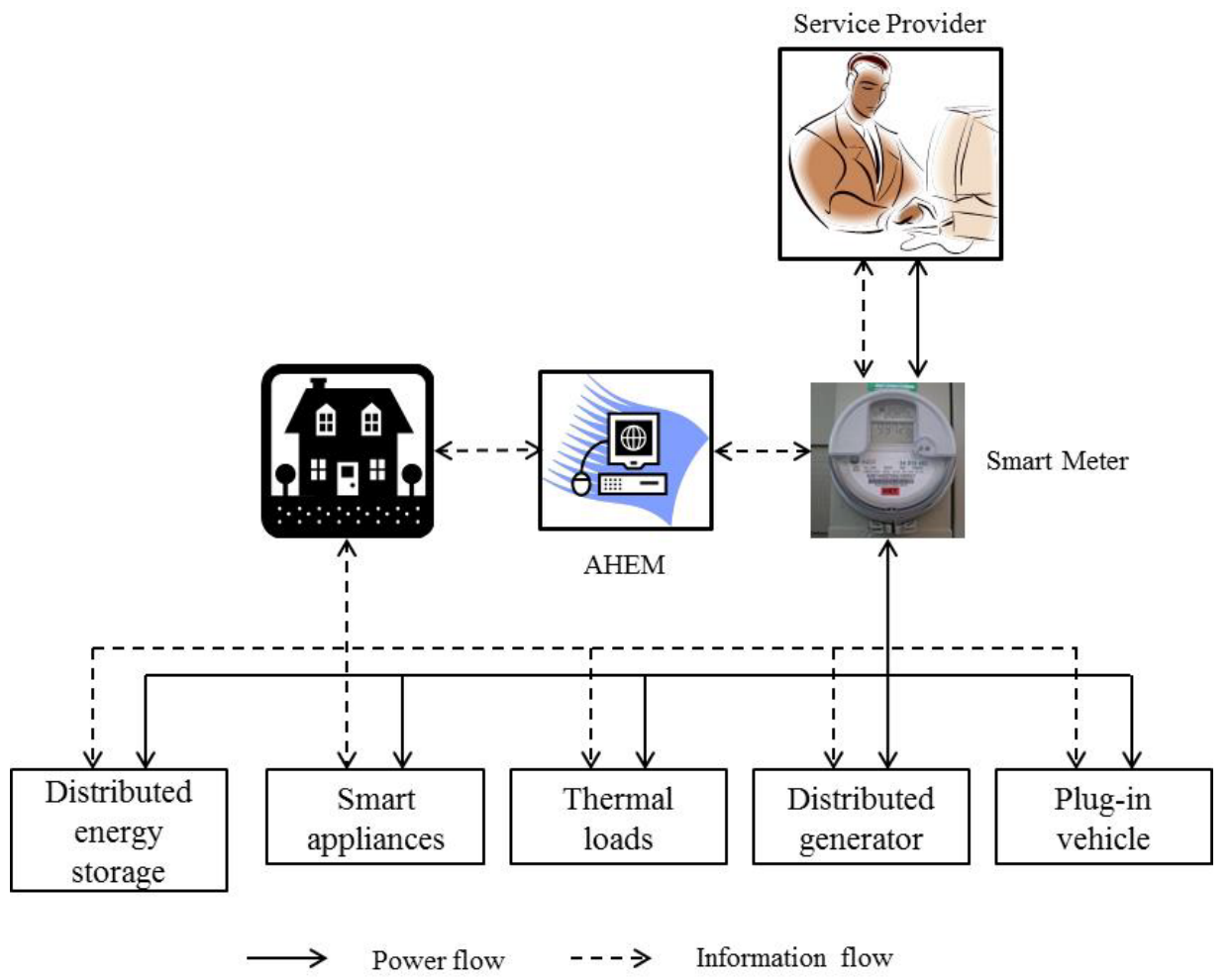

Fig. 4. Schematic diagram of a centrally controlled smart home adapted from [31]

If properly designed, controllers could also monitor loads and identify system issues, such as unexpected increases in power draw, current harmonics or vibration. Significant value - economic and personal - could be derived from identifying issues in advance of catastrophic failure.

For many utilities, a smart meter constitutes a smart grid. For others, these smart meters can be put to greater use and provide more substantial value to the utility, the grid, and the end-users via coordination. Analogously, smart homes may span the spectrum from the simple addition of discrete features - such as smart appliances or remotely controllable lighting and thermostats - to an automatically controlled, highly coordinated self-learning system with grid interaction. In the latter case, the control system serves as the brain of the smart home by automating domestic chores and providing sufficient feedback and communication. This symbiotic relationship improves the user's quality of life and allows active participation in bulk power system operations.

There are two schools of thought about the overall purpose of the smart home control system. The first school of thought posits that an ideal smart home control system should be entirely automated, predicting a user's every whim and reacting accordingly so as to maintain user-centered optimal comfort, convenience, and if applicable, savings [1]. One of the tenets of this prevailing theory envisions minimal user input. The control system may incorporate a machine learning algorithm to predict a user's desires as they occur. The second - and competing - school of thought envisions smart homes with well-informed and engaged users that value energy sustainability and are thus active participants in the everyday electricity management of the home [32]. In this case, the consumer is enabled with timely feedback on costs, energy, and emissions to influence the appropriate control strategy.

Machine learning [33], rule-based [34], multi-agent [35], and decision-making systems [31], constitute the state-of-theart in control strategy paradigms for the smart home. Although several smart home control systems are commercially available, they are currently cost prohibitive to the average consumer; these are expected to become affordable as enabling technologies mature.

\section{ENABLING TECHNOLOGIES}

Enabling technologies for smart homes mostly fall into two broad categories: utility-side and customer-side, and may be further enhanced through policy and legislation. Psychological and behavioral considerations (explained in detail in section V) could also greatly enhance the effectiveness of all the following enabling technologies.

\section{A. Utility-Side Enabling Technologies}

One of the most pressing issues for a utility company is the management of peak demand. From electricity generation to delivery, the electricity grid is designed to serve consumers during peak demand conditions; however for most of the time, the system is not used at full capacity, so a significant fraction of the system capacity idles. This is economically inefficient, as it requires large capital investments for peaking plants that are infrequently used, in some cases for only a few dozen 
hours per year, but that have to be maintained year-round. In the transmission and distribution realm, similar situations occur in the installation and maintenance of transmission lines, substations, transformers, distribution feeders and cables that are designed to accommodate infrequent peak conditions.

Smart homes are expected to aid utility companies through the ability to dynamically modify their electric energy consumption in response to grid conditions, allowing reductions in the output of peaking generation and transmission capacity. The savings introduced to utilities in the form of reduced capital investments as well as reduced purchase of expensive electricity from peaking generators in the spot market, will ultimately be passed to ratepayers.

There are two primary methods of modifying home energy consumption: total energy reduction through efficiency improvements or other measures; and peak demand shedding or shifting through some method of demand response (DR) activities. The former aims to reduce the amount of fuel consumed at power plants to produce electricity; the latter, explained in detailed in subsection 2, is of more interest to utilities since it reduces infrastructure requirements. These two methods are represented graphically in Fig. 5 with synthesized data for a typical residence. Potential energy efficiency schemes are portrayed by the dashed line (for 5\% uniform energy savings), and for a possible peak demand mitigation technique that uses approximately the same overall energy over 24 hours as the base case, but uses it at more optimal times than during the hours of system peak (indicated between 1600-2100 hours in Fig. 5).

Motivating residential customers to modify energy consumption habits is a difficult task that often has shown unexpected consequences. These will be discussed in more detail in section $\mathrm{V}$, but here the authors will outline the existing incentive methods.

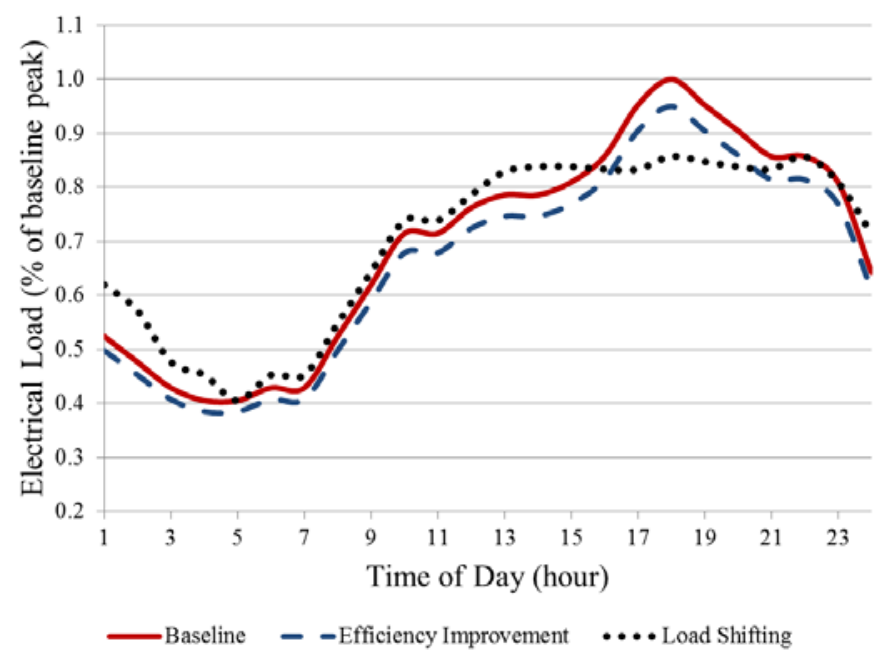

Fig. 5. Typical residential electrical load profile with base case, energy efficient case with uniform $5 \%$ energy savings, and load shifting case using approximately the same amount of energy but with peak shifted.

\section{1) Rates}

One tool that is traditionally used to influence demand of any commodity is its cost. For electricity utilities, each rate structure imposes specific requirements on the metering system to be implemented. Inclining-block, time-of-use (TOU), critical peak price (CPP), and peak-time-rebate (PTR) are the typical rate forms used to influence electricity demand.

Inclining block rates are designed so that the relationship between consumption and cost is non-linear, and discourages high consumption. This rate aims to reduce overall energy consumption and not peak demand. TOU rates, as the name suggests, change based on a set schedule. There are frequently three price buckets (low, medium, and high) corresponding to off-peak, mid-peak, and on-peak, respectively. TOU rates attempt to shift loads away from peak times, but they are not flexible enough to respond to dynamic operating conditions because the schedules are set far in advance. CPP rates address the dynamic conditions of the electricity grid by defining a "super peak" with very high costs. This encourages customers to shift loads and contribute to improving near real time operational conditions - such as system overload or peaking generator dispatch - to avoid higher costs. A PTR rate also contains super peak periods, but pays a rebate to the consumers based on the usage reduction relative to the projections. Advanced analytics including weather and usage patterns are used to predict what the consumer's usage would have been in the absence of a super peak period.

The effectiveness of these pricing structures at reducing residential energy or peak consumption is not well established, as AMI projects are relatively few. Different pilots indicate that residential consumers achieve the high peak reductions, especially in the summer, with the modified rate structures (CPP and PTR), and high satisfaction levels under the modified rates [36]. These dynamic rate structures and other enabling technologies can reduce utility side infrastructure investments, and therefore reduce electricity rates to consumers, simultaneously saving money for both sides.

\section{2) Demand Response}

In addition to rate structures, utilities may employ other strategies, such as DR, to mitigate peak load conditions. DR refers to a group of technologies and mechanisms that enable load curtailment or shifting in response to supply conditions. DR is particularly effective at reducing peak demand [37]. Contrary to energy efficiency, DR only aims at temporarily reducing load. In addition to rate structures, residential customers in smart homes can participate in DR via dispatchable mechanisms. Direct load control is generally used to mobilize capacity for load reduction, or for participating in ancillary services in the electricity market, e.g., for reserves. Because many household-scale loads are required to reach significant capacities of several MWs, energy service providers called aggregators sometimes operate such services. These aggregators (which are sometimes the utility) are 
required to enable customers to participate indirectly in energy markets [38] in exchange for financial compensation.

Loads can be curtailed or shifted in time by several means using direct load control. For thermal loads such as air conditioning or water heating, temperature settings can be temporarily changed so that the load is reduced (due to thermal inertia) or not used during the DR event, reducing electricity consumption compared to the baseline. Electric vehicle charging can also be rescheduled by postponing the beginning of the charge, by reducing the charging rate, or by simply not fully recharging the battery (in the case of a plugin hybrid electric vehicle) [39]. The use of smart appliances can also be shifted in time, e.g., a washing machine can be programmed to operate only when the electricity price is below a given threshold [40].

Depending on the mechanism used to achieve DR, a rebound effect may appear in the form of a large load peak after the end of the DR event [41]. This peak counters the purpose of a DR event, due to all the curtailed devices restarting their operation at the same time. Strategies such as cascading the beginning and end of the DR event for end-users can be used to mitigate this effect by lengthening and flattening this peak. However, these mechanisms may impact the habits and comfort of the user and cause acceptance issues. Temperature sensations vary from one person to the other, and what seems comfortable for one person may not be for another. DR mechanisms therefore need to take into account these constraints, for example, by allowing users to customize settings and set minimum and maximum values. These effects will be explored in section $\mathrm{V}$.

A proper use of DR mechanisms may help end-users reduce their electricity bills in exchange for a moderate impact on their comfort, while utilities can achieve significant savings by avoiding the need to build new generation capacity or to buy expensive peak power. Moreover, when demand exceeds capacity, DR can reduce the load with limited customer impact compared to traditional load shedding schemes.

\section{3) Smart Meters}

The above-described technologies rely on an enabling technology whose acceptance and implementation is accelerating: the smart meter (shown in Fig. 1). A smart meter provides the information and communication infrastructure to communicate in real time the operational and pricing information bi-directionally between the end-user and the service provider. Smart meters are usually capable of much more than this by including the ability to communicate with in-home appliances, programmable communicating thermostats (PCTs), and other loads.

Smart meters can record consumption data at intervals (as frequently as every minute) and automatically transfer the information to the utility over a secure network. Various communication architectures, including point-to-multipoint and mesh networks, have been implemented. This network, often in conjunction with a backhaul layer, provides two-way connectivity between the utility and the meter. The network also supports pushing signals to the meter, which could be used for an "on demand" reading to confirm power restoration after an outage, or to notify the meter of an upcoming "super peak" event.

When the meter is notified of an event, the information is communicated to appliances inside the customer's home using the meter's onboard ZigBee radio chip or other means. Based on pre-defined preferences or rules, different appliances can act to reduce or shift consumption in preparation for or during the "super peak" events.

\section{B. Customer-Side Enabling Technologies}

Customer-side enabling technologies can rarely exist on their own merits. They usually require at least one utility side enabling technology to predate them. For example, a smart appliance is of lesser use without a dynamic rate structure or smart meter. This has been somewhat of a stumbling block for the industry, as the chicken-or-the-egg causality argument has prevented significant adoption and investment on either side.

\section{1) Smart Loads}

Smart appliances are currently a fledging technology. A smart appliance is an end-use device that is connected to a HAN and may be able to automatically or remotely respond to signals from the utility or other sub-systems in the smart home. Different devices allow reduction or shifting of power consumption, including PCTs, which can change the set-point or cycle the air conditioning compressor based on notification of a "super peak" event. More advanced and intriguing options have been proposed for freezers and refrigerators, such as delaying the defrost cycle (often the highest demand mode of operation) to be scheduled away from "super peak" events.

A more advanced use of a PCT would be to lower the setpoint in advance of the initiation of the "super peak" event to pre-cool the house and then use the thermal inertia of the construction to coast during the event, without affecting comfort. Advanced analytics - including knowing the actual heat exchange rate of the building - may be required, though machine learning controls can effectively learn building thermal mass characteristics.

The significant investment required to outfit a home with smart appliances can be somewhat alleviated by retrofitting traditional appliances with smart plug-load switches. These devices have yet to standardize a communication protocol, with available devices using ZigBee, 802.11 class wireless local area network, Bluetooth, or power line communication protocols.

\section{2) Customer Portal}

The information collected by the smart meter may be of high value to the consumer, as it can help increase awareness of energy consumption. To make this information accessible 
and understandable, several utilities are introducing web portals that customers can use to access detailed information on their usage patterns, and often discover avenues of energy efficiency. Many commercial web portals include functionality such as analytics to increase energy efficiency based on consumption patterns, insights on why a bill increased, and historical bill information. Export functions - to integrate the raw data with third party applications for further analytical insights - are becoming common. These web portals often include a smartphone app, which is somewhat different from the browser based web portal, as the app is geared toward high frequency and low engagement transactions.

\section{Policy and Standards}

Changes to energy policies and available subsidies for retrofitting existing homes with smart appliances as well as building new homes with smart technologies are viewed as non-technological enablers. In the US, the Energy Policy Act of 2005, the Energy Independence and Security Act of 2007, and the American Recovery and Reinvestment Act of 2009 have all provided tax incentives, credits or deductions for residential energy efficiency upgrades.

Lack of industry-accepted device communication and interoperability standards is a critical barrier to more widespread adoption of smart home technologies. Several ISO and IEEE standards activities are underway or recently completed to begin addressing this barrier. Key among them are ISO/IEC 15045, 15067, 18012, and IEEE 2030.

\section{CONSUmer BeHAVIOR}

The impact of technological advancement is acknowledged as an important enabler for the expansion of smart homes, an integral part of the equation is influencing the behavior of the occupant vis-à-vis energy usage with information and education [32]. Feedback and automation are essential features of achieving this in a smart home. However, an optimal energy efficiency strategy requires both features be designed with the end-user in mind.

Numerous studies have examined the effect of diverse forms of feedback on residential electricity usage. Feedback has ranged from low-tech forms such as door hangers [42], to state-of-the-art in home displays (IHDs) [43]. Feedback has usually comprised the current and past electricity usage of the end-user, but has sometimes included normative information, such as comparisons to one's neighbors [44]. In some cases, feedback has been combined with TOU rates or other incentives [45]. Recent reviews have concluded that real time feedback can effectively deliver durable $4 \%$ to $9 \%$ reductions in residential electricity consumption [46]-[48]. However, utilities are challenged when predicting the energy savings that will be achieved through feedback programs because of limitations in the available data. This is critical as utilities attempt to make the case to already skeptical customers.
Although it is beyond the scope of this paper to extensively review these feedback studies, the authors point out some important differences among them and caution the reader about extrapolating from the average energy reductions obtained in these studies to wide-scale IHD deployment. In particular, feedback studies vary in their recruitment strategies and some have methodological features that limit their generalizability.

A critical aspect of feedback studies is whether participants opt-in or opt-out, i.e., some utility pilots randomly selected a group of customers to enroll in a pilot and allowed those customers to choose not to participate (opt-out) [49], [50]. In contrast, opt-in studies, which are more common, advertised the study and asked for volunteers [51]-[53]. This seemingly subtle difference in recruitment can profoundly affect the results. Opt-in studies have shown relatively consistent effects of feedback. For example, three opt-in studies have shown overall energy savings of $6 \%$ to $10 \%$ [52]-[54]. In contrast, two opt-out studies conducted in [49] and [50] showed no significant effect of IHDs on electricity consumption. This difference has been demonstrated across a variety of energy conservation programs showing that opt-in programs have larger participant impact but lower penetration than opt-out programs [44], [55].

Another important consideration for evaluating feedback studies is whether they include comparisons to a randomly assigned control group. However, the absence of comparisons to a control group is common [56], [57]. The HAN pilots of Salt River Project in Arizona and San Diego Gas \& Electric in California both report having control groups without comparisons between the treatment and control in the analyses [45], [58]. Moreover, some studies that include a control group are unable to yield valid comparisons. For example, [43] had three IHD conditions consisting of customers who opted in to the study; and, the IHD conditioned energy usage was compared to that of a control group selected from utility customers who did not volunteer for the study. These two sets of customers are likely to differ in important ways. Because [43] did not control for prior electricity usage, comparisons between the control and IHD groups are of limited use.

A major limitation to the work on feedback efficacy is the relative lack of long-term datasets that can help evaluate persistence [59]. For smart homes to realize their potential, consumers must be engaged, which may prove challenging. For example, a recent study examined the effectiveness of electricity consumption feedback by randomly assigning participants to feedback delivered via the now discontinued Google Powermeter web interface and control conditions [51]. The feedback consisted primarily of a graph that presented 10min interval and historical comparison data. However, other features were available, including projected electricity consumption during different time periods (e.g., night, morning) and for the whole year, a link to energy conservation tips and an email reminder. The results in [51] indicate that 
the effect of feedback wanes over time. Reductions in energy consumption of $8 \%$ were seen in the first week. Energy consumption had returned to baseline levels by the fifth week.

Concerns about the durability of behavior change feed the belief that the real solution to energy efficiency is automation. Automation will be an important component of smart homes and should not be viewed as a way to override the consumer but rather to increase the convenience of efficient choices [32]. Successful smart home design requires focusing on the idea that people use energy for important functions in their lives. Therefore, automation must allow consumers to reduce energy use without being perceived as interfering with these important functions. Otherwise, the end-user may circumvent the technology and reduce the efficiency of the smart home.

The construct of psychological reactance describes this phenomenon [60]. When individuals feel that their freedom is threatened, they act to restore that freedom. If people believe that the smart home is prohibiting them from living the way they wish, they may respond by overriding the programmable thermostat to manually set points higher than before it was installed. To prevent psychological reactance, the smart home must give the end-user choice. Allowing the end-user to customize the settings of smart appliances and especially allowing the user to opt-out of functions, such as a delayedstart on a dishwasher on a use-by-use basis, will be important to reduce psychological reactance.

In the case of energy efficiency, psychological reactance manifests through the "rebound effect" that occurs when technological improvements fail to live up to the expected energy savings because behavioral changes counteract the increased energy efficiency [61]. The authors differentiate the rebound effect mentioned from that mentioned in section IV with respect to DR.

Studies of the rebound effect for residential space heating show that energy savings fall short of expectations by 10 to $30 \%$. In particular, in lower income homes, families convert some of their new energy efficiency into greater comfort by increasing the wintertime thermostat set point [61]. This might seem counterintuitive to engineers and other professionals who define energy efficiency as "using less energy to provide the same service" [62]. However, consumers view efficiency as providing the functionality they desire for as little energy as possible [63]. In fact, increasing comfort was the top reason cited by California homeowners for pursuing energy efficient retrofits. Although comfort outranked the desire to reduce energy bills, reducing costs was also an important consideration [64]. Other studies have found that participants consistently cite saving money as a top reason for performing energy efficient retrofits such as insulating the attic [65], [66]. However, comfort is often overlooked and needs to be considered in smart home design because energy use varies as a function of tolerance for discomfort [63]. Although technology enables the development of smart homes, an integral part of the equation is influencing occupants' behavior.

\section{CONCLUSION}

Smart homes rely on numerous enabling technologies in both the electricity grid and consumer electronics. Standardization and maturity of the technologies in each of these realms is required if smart homes are to be pervasive. Given that buyin from users is a key that will unlock the adoption of smart homes, rigorous tests with consumers must be integrated into the smart home design procedure. Without the comprehensive multi-disciplinary assessment of the smart home, an expensive system may fall short of expectations.

\section{REFERENCES}

[1] R. Harper, Inside the Smart Home. Springer, 2003.

[2] U.S. Bureau of Labor Statistics, "Beyond the Numbers: Pricing and Spending," Oct. 2012.

[3]"Spending on Newspapers and Magazines Slides as Spending for Internet Access Soars," United States Department of Labor Bureau of Labor Statistics, Feb-2012. [Online]. Available: http://www.bls.gov/cex/newspapers.htm. [Accessed: 18-Dec-2012].

[4] U.S. Energy Information Administration, "Annual Energy Review 2011," Sep. 2012.

[5]"RECS Data Show Decreased Energy Consumption Per Household," United States Energy Information Administration, Jun-2012. [Online]. Available:

http://www.eia.gov/consumption/residential/reports/2009/consumptiondown.cfm. [Accessed: 18-Dec-2012].

[6] "CPI Inflation Calculator," United States Department of Labor Bureau of Labor Statistics. [Online]. http://www.bls.gov/data/inflation_calculator.htm. [Accessed: 21-Dec-2012].

[7] W. LeBlanc, "Customer Priorities and Behavior: kWhs, iPads, and Lattes," Fort Collins, Colorado, 25-Sep-2012.

[8] W. Mert, M. Watts, and W. Tritthart, "Smart Domestic Appliances in Sustainable Energy Systems - Consumer Acceptance and Restrictions," in Proceedings of the ECEEE 2009 Summer Study, 1751, vol. 1761.

[9] United States Congress, "Energy Independence and Security Act of 2007." United States Government Printing Office, Jul-2007.

[10] T. Hansen, R. Roche, S. Suryanarayanan, H. J. Siegel, D. Zimmerle, P. Young, and A. Maciejewski, "A Proposed Framework for Heuristic Approaches to Resource Allocation in the Emerging Smart Grid," presented at the IEEE PES International Conference on Power Systems and Technology (POWERCON 2012), Auckland, New Zealand, 2012, pp. 1-6.

[11] S. Gupta, M. S. Reynolds, and S. N. Patel, "ElectriSense: Single-Point Sensing Using EMI for Electrical Event Detection and Classification in the Home," in UbiComp 2010, Copenhagen, Denmark, 2010, pp. 139-148.

[12] M. Erol-Kantarci and H. T. Mouftah, "Wireless sensor networks for cost-efficient residential energy management in the smart grid," Smart Grid, IEEE Transactions on, vol. 2, no. 2, pp. 314-325, 2011.

[13] A. Chopra, "Modeling a Green Energy Challenge after a Blue Button," The White House, 15-Sep-2011. [Online]. Available: http://www.whitehouse.gov/blog/2011/09/15/modeling-green-energy-

challenge-after-blue-button. [Accessed: 18-Dec-2012].

[14] V. Atluri, U. Cakmak, R. Lee, and S. Varanasi, "Making Smartphones Brilliant: Ten Trends," McKinsey \& Company, 20, Jun. 2012.

[15] "Nucleus Home Energy Manager," GE Appliances. [Online]. Available: http://www.geappliances.com/home-energy-manager/. [Accessed: 19-Dec2012].

[16] "CPS Energy: A Consert Case Study," Consert, Inc., Sep. 2012.

[17] “ComEd RRTP Program Overview," ComEd, 2012. [Online]. Available: https://rrtp.comed.com/about/. [Accessed: 19-Dec-2012].

[18] "Recovery Act Smart Grid Project Information," SmartGrid.gov, 2012. [Online]. Available:

http://www.smartgrid.gov/recovery_act/project_information. [Accessed: 19Dec-2012].

[19] A. Marchiori, D. Hakkarinen, Q. Han, and L. Earle, "Circuit-Level Load Monitoring for Household Energy Management," IEEE Pervasive Computing, vol. 10, no. 1, pp. 40 -48, Mar. 2011. 
[20] K. Herter, P. McAuliffe, and A. Rosenfeld, "An exploratory analysis of California residential customer response to critical peak pricing of electricity," Energy, vol. 32, no. 1, pp. 25-34, 2007.

[21] Nest Labs, "Nest Learning Thermostate Efficiency Simulation: Update Using Data from First Three Months." Apr-2012.

[22] R. Yang and M. W. Newman, "Living With an Intelligent Thermostat: Advanced Control for Heating and Cooling Systems," in Proceedings of the 2012 ACM Conference on Ubiquitous Computing, 2012, pp. 1102-1107.

[23] U.S. Energy Information Administration, "Annual Energy Outlook 2012,” 0383 (2012), Jun. 2012.

[24] K. Yoshimi, M. Osawa, D. Yamashita, T. Niimura, R. Yokoyama, T. Masuda, H. Kondou, and T. Hirota, "Practical Storage and Utilization of Household Photovoltaic Energy by Electric Vehicle Battery," presented at the Innovative Smart Grid Technologies (ISGT), 2012 IEEE PES, 2012, pp. 1 -8. [25] I. Cvetkovic, T. Thacker, D. Dong, G. Francis, V. Podosinov, D. Boroyevich, F. Wang, R. Burgos, G. Skutt, and J. Lesko, "Future Home Uninterruptible Renewable Energy System With Vehicle-To-Grid Technology," in IEEE Energy Conversion Congress and Exposition, 2009. ECCE 2009, 2009, pp. $2675-2681$

[26] E. Cready, J. Lippert, J. Pihl, I. Weinstock, and P. Symons, "Technical and Economic Feasibility of Applying Used EV Batteries in Stationary Applications," Sandia National Laboratories, Albuquerque, NM, USA; Livermore, CA, USA, SAND2002-4084, 2003.

[27] J. Neubauer, A. Pesaran, and D. Howell, "Secondary Use of PHEV and EV Batteries - Opportunities \& Challenges," Orlando, Florida, USA, 19-May2010 .

[28] "Occupied Space Standards Overview," EMerge Alliance, 2012. [Online].

Available:

http://www.emergealliance.org/Standards/OccupiedSpace/Overview.aspx.

[Accessed: 19-Dec-2012].

[29] R. Noroozian, M. Abedi, and G. Gharehpetian, "Combined Operation of AC and DC Distribution System with Distributed Generation Units," 2010.

[30] M. A. Zehir and M. Bagriyanik, "Demand Side Management by Controlling Refrigerators and its Effects on Consumers," Energy Conversion and Management, vol. 64, pp. 238-244, 2012.

[31] J. M. Armas and S. Suryanarayanan, "A Heuristic Technique for Scheduling a Customer-Driven Residential Distributed Energy Resource Installation," presented at the Intelligent System Applications to Power Systems, 2009. ISAP '09. 15th International Conference on, 2009, pp. 1-7.

[32] S. S. Intille, "The goal: smart people, not smart homes," in Proceedings of the International Conference on Smart Homes and Health Telematics, 2006, pp. 3-6.

[33] J. Choi, D. Shin, and D. Shin, "Research and Implementation of the Context-Aware Middleware for Controlling Home Appliances," IEEE Transactions on Consumer Electronics, vol. 51, no. 1, pp. 301 - 306, Feb. 2005.

[34] A.-M. Vainio, M. Valtonen, and J. Vanhala, "Proactive Fuzzy Control and Adaptation Methods for Smart Homes," IEEE Intelligent Systems, vol. 23, no. 2 , pp. $42-49$, Mar. 2008

[35] S. Abras, S. Pesty, S. Ploix, and M. Jacomino, "An Anticipation Mechanism for Power Management in a Smart Home Using Multi-Agent Systems," in 3rd International Conference on Information and Communication Technologies: From Theory to Applications, 2008. ICTTA 2008, 2008, pp. $1-6$.

[36] "PowerCentsDC(TM) Program: Final Report," eMeter Strategic Consulting, Sep. 2010.

[37] F. Rahimi and A. Ipakchi, "Demand Response as a Market Resource Under the Smart Grid Paradigm," IEEE Transactions on Smart Grid, vol. 1, no. 1 , pp. $82-88$, Jun. 2010

[38] T. Nguyen, M. Negnevitsky, and M. de Groot, "Pool-Based Demand Response Exchange: Concept and Modeling," in 2011 IEEE Power and Energy Society General Meeting, 2011, p. 1

[39] S. Shao, M. Pipattanasomporn, and S. Rahman, "Grid Integration of Electric Vehicles and Demand Response With Customer Choice," IEEE Transactions on Smart Grid, vol. 3, no. 1, pp. 543 -550, Mar. 2012.

[40] H. Saele and O. S. Grande, "Demand Response From Household Customers: Experiences From a Pilot Study in Norway," IEEE Transactions on Smart Grid, vol. 2, no. 1, pp. 102 -109, Mar. 2011

[41] L. A. Greening, D. L. Greene, and C. Difiglio, "Energy Efficiency and Consumption - The Rebound Effect - A Survey," Energy Policy, vol. 28, no. 6-7, pp. 389-401, Jun. 2000.
[42] R. C. Battalio, J. H. Kagel, R. C. Winkler, and R. A. Winett, "Residential Electricity Demand: An Experimental Study," The Review of Economics and Statistics, vol. 61, no. 2, pp. 180-189, 1979.

[43] M. A. Alahmad, P. G. Wheeler, A. Schwer, J. Eiden, and A. Brumbaugh, "A Comparative Study of Three Feedback Devices for Residential Real-Time Energy Monitoring," IEEE Transactions on Industrial Electronics, vol. 59, no. 4, Apr. 2012.

[44] E. Carroll, E. Hatton, and M. Brown, "Residential Energy Use Behavior Change Pilot," Opower, Mar. 2009.

[45] "Home Area Network Pilots Process Evaluation - Final Report," Research Into Action, SDG0259.01, May 2012.

[46] K. Ehrhardt-Martinez and S. Laitner, "People Centered Initiatives for Increasing Energy Savings," 2010.

[47] A. Faruqui, S. Sergici, and A. Sharif, "The Impact of Informational Feedback on Energy Consumption - A Survey of the Experimental Evidence," Energy, vol. 35, no. 4, pp. 1598-1608, 2010.

[48] B. Foster and S. Mazur-Stommen, "Results from Recent Real-Time Feedback Studies," Results from Real-time Feedback Studies Foster MazurStommen, Washington, DC, USA, B122, Feb. 2012.

[49] M. Wakefield, G. Horst, and B. Neenan, "The Effect on Electricity Consumption of the Commonwealth Edison Customer Applications Program: Phase 2 Final Analysis," Electric Power Research Institute, Palo Alto, CA, 1023644, Oct. 2011.

[50] I. Matsukawa, "The Effects of Information on Residential Demand for Electricity,” The Energy Journal, pp. 1-17, 2004.

[51] S. Houde, A. Todd, A. Sudarshan, J. A. Flora, and K. C. Armel, "RealTime Feedback and Electricity Consumption: A Field Experiment Assessing the Potential for Savings and Persistence," The Energy Journal, vol. 34, no. 1, 2013.

[52] "Cape Light Compact: Residential Smart Energy Monitoring Pilot Final Report," PA Consulting Group, Madison, WI, USA, Mar. 2010.

[53] D. Parker, D. Hoak, and J. Cummings, "Pilot Evaluation of Energy Savings from Residential Energy Demand Feedback Devices," Florida Solar Energy Centre, Cocoa, Florida, USA, FSEC-CR-1742-08, 2008.

[54] D. Mountain, "The Impact of Real-Time Feedback on Residential Electricity Consumption: The Hydro One Pilot," McMaster Institute for Energy Studies, Ontario, Canada, Mar. 2006

[55] T. Scaramellino, "Scaling Behavior-Based Programs: The Tradeoffs of Opt-In vs. Opt-Out Design,” Washington, DC, USA, 2011.

[56] B. Norton, "PowerCost Monitor Pilot Program Evaluation," Opinion Dynamics Corporation, Waltham, MA, USA, Apr. 2008.

[57] L. Holmes, "NV Energy Update," Denver, CO, USA, 2008.

[58] B. Pruitt, "Salt River Project M-Power," Phoenix, AZ, USA, Nov2005 .

[59] W. Abrahamse, L. Steg, C. Vlek, and T. Rothengatter, "A Review of Intervention Studies Aimed at Household Energy Conservation," Journal of Environmental Psychology, vol. 25, no. 3, pp. 273-291, 2005.

[60] S. S. Brehm and J. W. Brehm, Psychological Reactance: A Theory of Freedom and Control. Academic Press New York, 1981.

[61] S. Sorrell, The Rebound Effect: An Assessment of the Evidence for Economy-Wide Energy Savings from Improved Energy Efficiency. UK Energy Research Centre London, 2007.

[62] "What is energy efficiency?," Lawrence Berkeley National Laboratory, 2012. [Online]. Available: http://eetd.lbl.gov/ee/ee-1.html. [Accessed: 19Dec-2012].

[63] Fleishmann-Hillard and Booz, "Transforming Awareness into Action: Consumer Perceptions of Energy Use in the Chicago Metropolitan Area," Smart Grid Consumer Collaborative, Nov. 2011.

[64] R. Knight, L. Lutzenhiser, and S. Lutzenhiser, "Why Comprehensive Residential Energy Efficiency Retrofits Are Undervalued," in Proceedings of the ACEEE Summer Study on Building Conference, Asilomar, CA, 2006.

[65] L. Arpan, J. Lu, A. Opel, and P. Steinberg, "Home Energy Conservation and Efficiency in Florida: A Survey of Residents' Behaviors, Intentions, Perceived Barriers, and Perceived Benefits," Florida State University, 2009.

[66] "Motivating Home Energy Improvements: Focus Groups for the U.S. Department of Energy," United States Department of Energy, 2010. 